\title{
Elementos materiais e simbólicos na mudança de escala da mobilização dos atingidos por barragens
}

\author{
Material and symbolic elements in the scale shift of the anti-dam movement \\ mobilization
}

\author{
Gerson de Lima Oliveira'
}

\section{Resumo}

Os movimentos sociais configuram um tema clássico de discussão nas ciências sociais. Entretanto, boa parte da literatura dá maior ênfase à análise dos elementos "materiais" da mobilização ou os analisa separadamente de seus elementos "simbólicos", não raro dando menor ênfase a estes. Quando a análise das duas dimensões se faz presente, é comum a apresentação de descrições importantes sobre a história e características dos movimentos sociais, mas com pouca atenção aos elementos explicativos de como a mobilização e a organização se estruturam. Com o objetivo de realizar uma pesquisa cujo foco esteja nas causas da sustentação e ampliação da mobilização, valemo-nos do conceito de mudança de escala para explorar o que aqui denominamos expansão organizativa e amplificação simbólica como mecanismos causais que possibilitam a um movimento social sustentar-se e ampliar sua mobilização. Para tanto, foi realizada uma pesquisa sobre a mudança de escala na mobilização dos atingidos por barragens na bacia do rio Uruguai, que culminou na fundação do Movimento dos Atingidos por Barragens (MAB). Ancorada na noção de causalidade preconizada pelo realismo crítico, procuramos responder à seguinte questão de pesquisa: como se dá a transformação de um determinado movimento social envolvido em conflitos pontuais em um ator de maior alcance, imbuído de objetivos, pautas e bandeiras políticas diversas? Para tanto, exploramos os mecanismos da expansão organizacional e, sobretudo, da amplificação simbólica para explicar como os atingidos por barragens enquadram o problema social que os atinge e produzem sensos de justiça e justificações para sua mobilização.

Palavras-chave: Mudança de Escala, enquadramento interpretativo, mobilização social, movimentos sociais, mecanismos causais.

\begin{abstract}
The social movements are a classic debate in the field of social sciences. However, much of its literature places greater emphasis on the analysis of "material" elements of the mobilization or instead analyze its "symbolic" elements separately, not infrequently conceding only minor emphasis to the latter. When the analysis of both dimensions takes place, we usually have the rendition of relevant descriptions on the history and characteristics of the social movements, nevertheless with scarce consideration to the explicative elements on how the mobilization and the organization are structured. Aiming to conduct research which focuses on the causes of the sustaining and enlargement of the mobilization, we had recourse to the concept of scale shift to explore what we name organizational expansion and symbolic
\end{abstract}

1 Professor da Universidade Federal do Pampa (UNIPAMPA) e membro dos grupos de pesquisa Associativismo Contestação e Engajamento (GPACE), t3xto, Espaços Deliberativos e Governança Pública (GEGOP) e Sociedade, Educação e Desigualdades (SOCIEDUDES). E-mail: gerson.oliveira@ufrgs.br. Cidade: São Borja. 
Elementos materiais e simbólicos na mudança de escala da mobilização dos atingidos por barragens | Gerson Lima de Oliveira

amplification as causal mechanisms which enables a social movement to sustain itself and to enlarge its mobilization. To do so, we carried out a research study on the scale shift in the mobilization of the population affected by dams on the Uruguay River basin its expansion on the founding of the Movimento dos atingidos por Barragens - MAB - (Movement of People Affected by Dams). Anchored in the notion of causality professed by critical realism, we sought to answer the following research question: how does a given social movement concerned with specific conflicts transforms itself into a player of greater reach, imbued with dissimilar objectives, agendas and policies? Therefore, we inquired into the mechanisms of the organizational expansion and especially of the symbolic amplification to explain how those affected by dams frame the social problem that impacts them and develop senses of justice and justifications for their mobilization.

Keywords: Scale shift, interpretative frames, social mobilization, social movements, causal mechanisms.

\section{Introdução: a mobilização dos atingidos por barragens e os mecanismos da ação coletiva}

Os $1262 \mathrm{~km}$ ao longo do curso do Rio Uruguai² (dentro do território brasileiro), que fazem a divisa dos Estados do Rio Grande do Sul com Santa Catarina, e mais adiante, a fronteira do Brasil com a Argentina, é desde a década de 1970 alvo de projetos que visavam a construção de 23 usinas hidrelétricas $^{3}$ (UHEs) em sua bacia hidrográfica até o ano 2010, com o objetivo de suprir a demanda populacional e industrial por energia elétrica (ROCHA, 2014). Atualmente, quatro destas hidrelétricas estão em operação explorando o potencial hídrico do Rio Uruguai (UHE Itá, UHE Machadinho, UHE Foz do Chapecó e Represa de Salto Grande); e mais três em seus afluentes: UHE Passo Fundo (rio Passo Fundo), UHE Monjolinho (rio Passo Fundo) e UHE Campos Novos (rio Canoas). As demais estão em processo de planejamento, negociação ou inventariação. ${ }^{4}$

\footnotetext{
2 O Rio Uruguai tem ao todo cerca de $1770 \mathrm{~km}$ de extensão, desconsiderando os rios que, em junção, lhe dão origem: o Rio Pelotas e o Rio Canoas, nas regiões Nordeste do Rio Grande do Sul e Sudeste de Santa Catarina. Se for considerada a extensão do rio Pelotas, sua extensão chega aos $2150 \mathrm{~km}$ (Plano Nacional de Recursos Hídricos, 2006).

3 De acordo com o sistema Eletrobrás, umausina hidrelétricapode ser definida como um conjunto de obras e equipamentos cuja finalidade é a geração de energia elétrica, através de aproveitamento do potencial hidráulico existente em um rio. Para Benincá (2011, p.28). Uma barragem consiste em uma barreira artificial feita em cursos de água para a retenção de grandes quantidades de água. A sua utilização é, sobretudo, para abastecer de água zonas residenciais, agrícolas, industriais, produção de energia elétrica ou regularização de um caudal.

Fonte: http://www.furnas.com.br/hotsites/sistemafurnas/usina_hidr_funciona.asp

4 O Plano 2010 elaborado pela Eletrobrás em 1979 previa a construção de cerca de 200 usinas hidrelétricas por todo o território nacional, sendo 23 delas na Bacia do Rio Uruguai. Atualmente existem na Bacia do Rio Uruguai 21 usinas em operação ou construção (entre UHEs e Pequenas Centrais Hidrelétricas- PCHs) e cerca de 149 sendo inventariadas. Atualmente existem cerca de 180 grandes UHEs em operação no território nacional.
} 
Elementos materiais e simbólicos na mudança de escala da mobilização dos atingidos por barragens | Gerson Lima de Oliveira

A instalação de uma usina hidrelétrica consiste em um processo complexo, tanto no que diz respeito à dimensão técnica (engenharia civil, mecânica e elétrica), quanto em relação aos significativos impactos socioambientais que provoca. A construção de uma barragem implica em transformações profundas na geografia local, tais como a mudança no curso de um rio e o alagamento de porções de terra ocupadas pela fauna, flora e grupos populacionais humanos, resultando em expressivas interferências ambientais, no desterro e consequente migração involuntária (ou forçada) dos atingidos pelas barragens. Dentre os principais motivos que levam os atingidos a se mobilizarem está reivindicação da manutenção de seus modos de vida, já que se tratam - em sua maioria - de pequenos agricultores, pescadores, ribeirinhos, quilombolas e populações indígenas. A inundação de seus territórios, portanto, ameaça diretamente seus modos de vida e subsistência, ocasionando incomensuráveis (e muita vezes irreversíveis) danos materiais e simbólicos.

Se os impactos de uma só UHEsão suficientes para colocar em risco a manutenção de diferentes modos de vida, a escolha da bacia do Rio Uruguai como região a ter seus recursos hídricos intensamente explorados teve como consequência a expressiva mobilização social das populações que tradicionalmente habitam a região em um processo que se estende por mais de $40 \operatorname{anos}^{5}$. Neste sentido, esta pesquisa consiste em um estudo sobre o processo de mudança de escala (scale shift) na mobilização das populações atingidas por barragens na bacia do Rio Uruguai. A questão sociológica que a orienta é definida da seguinte forma: como se dá a transformação de um determinado movimento social envolvido em conflitos pontuais em um ator de maior alcance, imbuído de objetivos, pautas e bandeiras políticas diversas?

\footnotetext{
5 De acordo com Hüffner e Engel (2011), as sete UHEs em operação na Bacia do Rio Uruguai atingiram os territórios e as populações de 50 municípios da região, contabilizando um número aproximado a 11632 famílias atingidas, cifra que pode ser maior devido ao conhecimento de casos não contabilizados.
} 
Elementos materiais e simbólicos na mudança de escala da mobilização dos atingidos por barragens | Gerson Lima de Oliveira

A partir desta questão consideram-se dois eixos de análise que correspondem: [1] ao processo de mudança na escala da organização ao longo do tempo; e [2] ao processo de construção de justificativas para a mobilização ancoradas na construção de sensos de justiça e enquadramentos interpretativos. O primeiro diz respeito ao que aqui chamamos de expansão organizativa, que significa o crescimento da organização dos atingidos por barragens em termos de estrutura e alcance da ação. O segundo eixo denominamos amplificação simbólica ${ }^{6}$ e diz respeito às transformações argumentativas e simbólicas sob as quais os atingidos organizados atribuem significado ao problema social que os atinge, aos seus opositores, à sua própria organização, às reivindicações que pleiteiam e aos objetivos que defendem.

Com a questão de pesquisa proposta está o interesse em explorar como os agentes engajados em movimentos sociais se mobilizam, manejam repertórios, discursos previamente existentes e, a partir deles, criam novas formas de mobilização embasadas em novos elementos discursivos. $\mathrm{O}$ foco de análise no produto das ações coletivas tende a apresentar resultados que vão além da constatação dos elementos prévios supostamente condicionantes da ação coletiva. O esforço consiste em apresentar uma explicação causal dos elementos presentes no processo de mudança de escala da ação coletiva, tendo como estudo de os atingidos por barragens na bacia do Rio Uruguai; assim como os mesmos mobilizam elementos discursivos e produzem práticas orientadas a partir dos sensos de justiça por eles estabelecidos. Ao produzirem discursos que embasam sua ação, os militantes inscrevem-se em arenas de disputa em torno de temas como desenvolvimento, justiça social, sustentabilidade, direito à terra e defesa de modos de vida. A relação entre discurso e prática é empregada nesta pesquisa considerando a materialidade simbólica dos fenômenos sociais.

\footnotetext{
6 Pensamos este conceito a partir da definição do amplificador eletrônico, que se trata de um equipamento que intensifica e aumenta sons ou sinais de áudio e vídeo. A ideia está justamente na capacidade de ampliação do raio de alcance de uma mensagem e, sobretudo, na sua difusão. Todavia, esta capacidade é aqui entendida não somente como ampliação do raio de alcance de uma mesma mensagem, mas também na incorporação de novos elementos que podem transformá-la durante a amplificação.
} 
Elementos materiais e simbólicos na mudança de escala da mobilização dos atingidos por barragens | Gerson Lima de Oliveira

Assumir tal posição na pesquisa não significa que os argumentos mobilizados pelos agentes contenham verdade intrínseca à priori. São os atores que julgam os fenômenos a partir de suas concepções de mundo e assim criam sensos de [in]justiça sobre os impactos que os fenômenos sociais produzem (IBARRA; KITSUSE, 1993).

A partir da construção discursiva, os agentes vão tecendo práticas nas quais apresentam elementos identitários manifestados tanto nos objetivos do movimento, quanto na maneira como se engajam pessoalmente e dão sentido à sua atuação enquanto militantes. Aqui, racionalidade, lógica e elementos emotivos estão juntos no processo de construção discursiva a partir da qual os militantes agem enquanto movimento e produzem transformações na própria organização - provocando a mudança de escala a partir da difusão dos seus objetivos. Em uma via de mão dupla, expansão organizativa e amplificação simbólica integram um mesmo processo, o da mudança de escala, influenciando-se mutuamente e estabelecendo relações de causalidade que permitem sua explicação.

O conceito de mudança de escala carrega consigo a ideia de que a organização e mobilização dos atingidos por barragens passam por transformações materiais e simbólicas ao longo do tempo. Para tanto, as noções de processo e de causalidade cumprem papel importante neste sentido: de acordo com Tarrow e McAdam (2005), há uma diferença tácita entre os estudos clássicos sobre os movimentos sociais - que buscavam identificar elementos/variáveis estruturais e culturais que operariam como condições necessárias e/ou suficientes para a ação coletiva - e as pesquisas que direcionam o foco de análise ao inventário de eventos, processos e mecanismos ${ }^{7}$ que podem apresentar-se em maior ou menor grau nas ações coletivas contestatórias de forma geral. Para McAdam, Tarrow e Tilly (2001, p.11) a ideia de mecanismo pode ser definida como "a delimited class of events that alter relations among specified elements in identical or closely

\footnotetext{
${ }^{7} \mathrm{Em}$ linhas gerais, os mecanismos são tipos específicos de ação praticadas pelos agentes - a partir de suas capacidades e/ou disposições -, que produzem mudanças na realidade em um determinado sentido (MARCHAMER; DARDEN; CRAVER, 2000).
} 
Elementos materiais e simbólicos na mudança de escala da mobilização dos atingidos por barragens | Gerson Lima de Oliveira

similar ways over a variety of situations"; e processo como "recurring combinations of such mechanisms that can be observed in a variety of episodes of contentious politics" (McADAM; TARROW; TILLY, 2001, P.11) ${ }^{8}$. Dentre os mecanismos da ação coletiva contestatória, os autores identificam a mudança de escala como um dos mais importantes e a definem como "a change in the number and leve lof coordinated contentious action sleading to broader contention involving a wider range of actors and bridging their claims and identities." (McADAM; TARROW; TILLY 2001, p.331)99.

Tornar uma demanda política aceitável e relevante implica na articulação de sentidos e significados que buscam fazer das reivindicações algo inteligivel e legítimo à esfera pública; ou seja, convincente no sentido de conquistar a simpatia ou a adesão de individuos e grupos alheios ao movimento, mas que podem tornar-se simpatizantes da causa, apoiá-lo abertamente ou até mesmo converterem-se em militantes. No âmbito da sociologia, os estudos em torno da construção de enquadramentos interpretativos têm sido um dos principais suportes teórico-metodológicos mobilizados para a explicação de como agentes organizados em movimentos sociais compartilham ideias e objetivos comuns que sustentam sua mobilização, sobretudo no que diz respeito à defesa de uma alternativa aos argumentos hegemônicos sobre desenvolvimento e justiça.

De acordo com Benford e Snow (2000), o conceito de quadro interpretativo aplicado ao estudo das ações coletivas serve para a compreensão de três dimensões centrais: [1] a como os agentes diagnosticam (e constroem) determinado problema social; [2] como propõem soluções viáveis a este problema; e [3] como fomentam o engajamento. Desta forma, os autores definem o conceito de enquadramento interpretativo da ação

\footnotetext{
8 Isto é, ao invés de buscar elementos estáticos que funcionariam como determinantes da ação coletiva, os autores defendem que o papel da análise deveria ser o de identificar mecanismos dinâmicos que podem operar conjuntamente - dependendo do contexto - na formação de processos nos quais os agentes desencadeiam mobilizações, protestos e formam organizações.

9 Ou seja, a mudança de escala envolve tanto alterações organizativas (aumento do alcance de ação do movimento, incorporação de novos atores, complexificação da estrutura organizacional, etc.), quanto transformações nos fundamentos simbólico-culturais que definem a identidade do movimento.
} 
Elementos materiais e simbólicos na mudança de escala da mobilização dos atingidos por barragens | Gerson Lima de Oliveira

coletiva como elementos que "inspiram e legitimam atividades e campanhas de um movimento social" (BENFORD; SNOW, 2000).

Desde outra matriz epistemológica, Luc Boltanski apresenta uma análise dos processos de construção de significados da ação de forma um tanto comparável no conteúdo em relação à ideia dos quadros interpretativos, mas distinta em relação aos seus pressupostos. Se, por um lado, os autores anteriormente mencionados estão mais atentos aos mecanismos constituintes e às condições de possibilidades da formação de quadros interpretativos, por outro lado, a sociologia pragmática de Boltanski estaria mais interessada nos efeitos produzidos por uma determinada forma de justificação, o que não impede a análise dos elementos presentes na construção das justificativas.

Ainda que dificil comparar em termos epistemológicos e metodológicos por se tratarem de escolas sociológicas distintas, tanto Benford (1997) quanto Boltanski $(1991$; 1999) partem do princípio de que os significados que os atores atribuem aos fenômenos sociais estão o tempo todo em disputa. No caso desta pesquisa, temos dois polos antagônicos (ainda que o número de atores em disputa possa ser muito maior): de um lado, as populações atingidas pelo empreendimento e, de outro, as grandes corporações cujo negócio é a construção de barragens e a exploração de recursos hídricos.

Para justificar cada uma das posições, os agentes de ambos os lados precisam mobilizar argumentos a partir de ordens de grandeza já existentes, mas passiveis de adequação, contextualização ou mesmo transformação. Um lado, por exemplo, mobiliza discursos referentes a ideias de defesa do crescimento econômico, da promoção do desenvolvimento, do progresso ou da necessidade de ampliação do modelo energético existente para que o modo de vida hegemônico não colapse; enquanto o outro lado mobiliza sensos de justiça referente ao direito de permanecer nas áreas onde tradicionalmente vivem, critica o modelo energético vigente, apresenta a 
Elementos materiais e simbólicos na mudança de escala da mobilização dos atingidos por barragens | Gerson Lima de Oliveira

necessidade de se transformar este modelo e defende o direito de não terem seus meios de vida impactados pelo avanço do modelo hegemônico.

A definição dos parâmetros de justiça só pode se dar a partir da capacidade de cada um dos lados mobilizar elementos argumentativos capazes de [re]significar o fenômeno enquanto ato de necessidade ou [in]justiça. A consolidação de argumentos convincentes em relação ao fenômeno pode não somente orientar a ação dos atores envolvidos, mas também dos não envolvidos diretamente no conflito, assim como produzir ações práticas efetivas na arena sociopolitica que podem definir os rumos do conflito. Seguindo a linha argumentativa de Boltanski, a complexificação do discurso dos atingidos por barragens não estaria somente ligada a um processo de "tomada de consciência" (nos moldes do marxismo clássico), mas também à capacidade de articulação dos seus militantes que ao entrarem na arena de disputas acerca da discussão em relação às barragens, são levados a [re]qualificarem frequentemente seu discurso em relação ao polo oposto de disputa na busca por legitimidade.

A mudança de escala do movimento implica, assim, que ele passe a disputar sensos de justiça com opositores tão ou mais influentes do que ele, o que é fundamental para o estabelecimento de parâmetros sob os quais se firmam alianças e se conquistam simpatizantes. Além do mais, a disputa em termos simbólicos define regimes de veracidade sob um determinado fenômeno sob os quais outros atores (aliados, simpatizantes e opositores) passam a pautar suas próprias ações. A difusão dos sensos de [in]justiça a arenas mais abrangentes de disputa - ou seja, que envolvem diversos atores influentes no debate público - através do mecanismo da mediação é um dos elementos fundamentais que, por um lado, explica o crescimento do movimento e que, por outro, reflete sua capacidade de disputar regimes de veracidade com seus opositores.

\section{A expansão organizativa dos atingidos por barragens}

Entende-se por expansão organizativa no âmbito desta pesquisa todo o processo pelo qual a mobilização e organização dos atingidos por 
Elementos materiais e simbólicos na mudança de escala da mobilização dos atingidos por barragens | Gerson Lima de Oliveira

barragens logra sustentar-se através da ampliação de suas estruturas materiais. A mobilização das populações atingidas por barragens na bacia do Rio Uruguai inicia em meados da década de 1970 e se expande a partir da formalização de organizações como a Comissão Regional dos Atingidos por Barragens (CRAB), na primeira metade dos anos 80 e que, em 1991, originou o Movimento dos Atingidos por Barragens (MAB). Este, atualmente, atua em todas as regiões do país e consiste no maior e mais expressivo movimento social aglutinador da organização dos segmentos atingidos por barragens. $\mathrm{O}$ MAB não representa a totalidade dos atingidos, mas ilustra a mudança de escala na sua organização, na medida em que se constitui enquanto um ator articulado em todas as regiões do país e protagoniza ações que colocaram as reivindicações dos diversos segmentos atingidos na agenda política nacional.

O processo de mudança de escala potencializado a partir da ação do MAB consiste em um caso empírico bastante ilustrativo da questão de pesquisa apresentada na introdução. Dentre os principais mecanismos dinâmicos que compõem o processo de mudança de escala, Sidney Tarrow e Doug McAdam (2005) apresentam as já referidas difusão e mediação, além do mecanismo de alinhamento/formação de coalizão, que diz respeito à capacidade de um determinado movimento social compor blocos de ação com outros movimentos com causas similares ou transversais às suas. Como veremos mais adiante, junto com os demais mecanismos, a formação de coalizão também compõe um dos elementos que possibilitaram ao MAB mudar de escala.

\section{Amplificação simbólica}

Por amplificação simbólica denominamos o mecanismo pelo qual os atores envolvidos em disputas sociais logram difundir suas reivindicações e relacioná-las a outras bandeiras políticas semelhantes ou mais abrangentes que suas demandas particulares. Ela também abrange outros mecanismos auxiliares tais como o enquadramento, a justificação, a performance e a difusão. Na abrangência desta pesquisa, empregamos a amplificação 
Elementos materiais e simbólicos na mudança de escala da mobilização dos atingidos por barragens | Gerson Lima de Oliveira

simbólica com o objetivo de compreender e identificar como movimentos sociais ampliam e expandem suas bandeiras politicas relacionando-as a questões que transcendem suas demandas mais específicas. O caso dos atingidos por barragens - sobretudo através do MAB - expressa um exemplo bastante característico neste sentido.

No processo de expansão da mobilização dos atingidos por barragens, além da já referida expansão organizativa, a amplificação simbólica também corresponde a uma das dimensões explicativas deste processo. Ela diz respeito, basicamente, à maneira como os atingidos relacionam o problema social que os afeta a processos mais abrangentes/sistêmicos. Portanto, analisar como se dá a amplificação simbólica no âmbito da mobilização dos atingidos por barragens significa explorar os mecanismos acionados que possibilitam relacionar um problema específico - o desterro e demais danos ocasionados pela construção de barragens - com processos relacionados às políticas de desenvolvimento e ao próprio funcionamento do capitalismo.

Dentre os mecanismos que compõem a amplificação simbólica, caracterizamos resumidamente o enquadramento como a identificação de elementos, processos ou fenômenos sociais e a capacidade de atribuir sentido a eles; a justificação como a capacidade de atribuir sentido a um determinado problema/processo/fenômeno a partir de determinadas gramáticas que buscam conferir legitimidade, reconhecimento e justiça a uma determinada demanda; a performance como capacidade/habilidade de se articular ações públicas coordenadas que abrangem o universo simbólico de um determinado grupo ou movimento social expressando sentimentos, identidades e intencionalidades compartilhadas coletivamente; e a difusão que corresponde à capacidade de um determinado grupo ou movimento fazer ecoar publicamente suas reivindicações.

\section{Pressupostos teóricos de pesquisa}

Do ponto de vista epistemológico, considera-se nesta pesquisa que a ontologia dos fenômenos sociais é passível de compreensão, análise e explicação, ainda que o exercício de investigação também implique na 
Elementos materiais e simbólicos na mudança de escala da mobilização dos atingidos por barragens | Gerson Lima de Oliveira

construção do próprio objeto de pesquisa. Como sustentam alguns expoentes contemporâneos do realismo crítico (ARCHER, 1995, 1998; BHASKHAR, 1989; VANDENBERGHE, 2010), uma via não exclui a outra e a consideração dos dois pressupostos evita que a pesquisa sociológica resulte em um idealismo relativista fértil em termos propositivos, mas pouco eficaz no que diz respeito à produção de relações entre teoria e empiria para além da materialidade das ideias. Por outro lado, não se deixa cair na ingenuidade do empirismo positivista que pressupõe uma suposta "essência do objeto" que falaria por si só na voz do investigador e desconsidera o fato de que, na impossibilidade de um acesso à "realidade" que não seja interpretativamente mediado, todo recorte de pesquisa é uma construção e um enquadramento.

Nesta pesquisa, assume-se o pressuposto de que o confronto entre as populações atingidas por barragens e seus opositores é construído, mas também é fruto de fenômenos que existem para além da maneira como os indivíduos e grupos o interpretam. Sob a sustentação desta posição é preciso considerar que há uma complexa relação entre construção de um determinado problema e a existência ontológica do mesmo, a partir da qual um debate se faz necessário: o da confrontação e/ou complementação entre construção de problemas sociais e tomada de consciênciados mesmos.

Efetivamente, sustenta-se aqui que no conflito social estabelecido entre atingidos por barragens e seus opositores há uma dimensão construída do problema social que passa pelo crivo dos enquadramentos interpretativos mobilizados pelos atores, seus argumentos, justificações, objetivos, sensos de justiça e visões de mundo. Por outro lado - de forma complementar, mais que em oposição - está colocada uma dimensão ontológica concreta do problema que os atores vão conhecendo à medida em que nele se envolvem. Isto fica evidente quando nas arenas de disputas os agentes dedicam-se a desconstruir os discursos e as práticas dos seus oponentes através da apresentação de argumentos e informações baseadas em elementos factuais. 
Elementos materiais e simbólicos na mudança de escala da mobilização dos atingidos por barragens | Gerson Lima de Oliveira

No caso dos atingidos, colocar em xeque a ideia de desenvolvimento enquanto prática e discurso é não somente construir uma posição ideal de contraponto, mas também problematizar e tomar consciência em relação à defesa aparentemente desinteressada da naturalidade, inevitabilidade ou necessidade de realização de um determinado modelo dedesenvolvimento. Existem atores interessados e grupos econômicos obtendo ganhos econômicos de fato com os impactos gerados sobre as populações atingidas. Por outro lado, os empresários do ramo da construção civil e da produção de energia elétrica argumentam que os atingidos se mobilizamna defesa de interesses particularistas e que os beneficios do desenvolvimento seriam mais importantes para o "bem comum" que seus possiveis efeitos colaterais.

Em outras palavras, os significados do conflito podem ser mobilizados de acordo com a capacidade que os agentes envolvidos dispõem para mobilizar argumentos e assim enquadrar a realidade. Entretanto, a realidade do conflito em si não reside somente na dimensão concreta das ideias: está sujeita à maneira como os distintos grupos envolvidos são capazes de esmiuçar a relação existente entre o discurso e a prática dos seus oponentes. Este exercício - propõem-se aqui - é obra tanto de uma construção conceitual realizada pelos atores envolvidos, quanto de um processo de tomada de consciência dos desdobramentos concretos do conflito em questão, que são base de um denominador comum sobre o qual os atores em conflitos mobilizam justificativas e oferecem soluções, isto é, os elementos factuais.

Todavia, para os realistas críticos a "tomada de consciência" não está na coisa em si. $O$ entendimento dos fenômenos sociais se dariapela experiência que temos ao vivenciá-los, na forma como eles nos afetam e como nós atribuímos significados a eles. Isto significa que as coisas do mundo existem, que são passíveis de uma ontologia, mas não têm um significado inerente único e universal. Aqui nos parece caro um dos princípios da fenomenologia de Husserl (1992) ${ }^{10}$, a saber, de que os fenômenos são apreendidos através da experiência de agentes capazes de

10 A primeira edição é de 1913. 
Elementos materiais e simbólicos na mudança de escala da mobilização dos atingidos por barragens | Gerson Lima de Oliveira

apreender as coisas do mundo e atribuir-lhes significado. Obviamente, o significado atribuído é compartilhado socialmente e mediado pela linguagem e não fruto do "golpe de genialidade" de um sujeito autônomo capaz de captar uma suposta "essência" das coisas, como postulavam os positivistas.

Ou seja, as possibilidades de interpretação e enquadramento são múltiplas e indissociáveis da experiência dos atores. Entretanto, existem elementos factuais que são elementos de parâmetro comum para os distintos enquadramentos possíveis. Portanto, não deveríamos levar em conta a "tomada de consciência" e a construção do problema como dicotomias. Ambas fazem parte de um mesmo processo mediado pela experiência dos atores diante de um acontecimento ou fenômeno concreto.

\section{Procedimentos metodológicos}

Esta pesquisa foi realizada por meio de trabalho de campo (entrevistas e observações) e de pesquisa documental. As observações e participações foram realizadas em seminários, congressos e protestos nas cidades de Porto Alegre, Florianópolis e São Paulo e as entrevistas e demais observações foram realizadas nas regiões do Alto Uruguai (Erechim/RS), do Contestado (Campos Novos e Celso Ramos/SC) e do Oeste Catarinense (Chapecó, Águas do Chapecó, São Carlos e Itapiranga). Foram realizadas entrevistas com atingidos, dirigentes do MAB, profissionais colaboradores do movimento e pesquisadores que estudam o caso dos atingidos por barragens. A pesquisa documental foi realizada em materiais de divulgação, jornais, estudos, dados levantados e material multimídia produzidos pelo $\mathrm{MAB}$; revistas, relatórios, livros, teses e dissertações disponibilizadas em universidades e bibliotecas públicas de cidades atingidas ou que são polo migratório de atingidos (Erechim/RS, Chapecó/SC, Campos Novos/SC e Tubarão/SC); além de pesquisa realizada na biblioteca da Eletrosul em Florianópolis. A análise de materiais produzidos pelos atingidos primou pela comparação entre enquadramentos, demandas manifestadas e 
Elementos materiais e simbólicos na mudança de escala da mobilização dos atingidos por barragens | Gerson Lima de Oliveira

posicionamentos políticos ao longo do tempo. As informações obtidas foram processadas com o auxílio do programa de análise qualitativa NVivo 10.

As entrevistas realizadas foram do tipo semiestruturada ${ }^{11}$ e em profundidade ${ }^{12}$, com questões pautadas em um roteiro, a partir do qual direciona-se a entrevista para a exploração dos aspectos considerados importantes e necessários para a pesquisa. O critério de seleção dos entrevistados obedeceu aos seguintes quesitos: 1) Trajetória de engajamento/militância na causa dos atingidos por barragens; 2) conhecimento acerca da história da mobilização dos atingidos na bacia do rio Uruguai ou trajetória de pesquisa sobre o tema e; 3) indicação dos entrevistados anteriores. Estas informações não são apenas "captadas", mas, sobretudo, interpretadas e reconstruídas pelo pesquisador. Nesse percurso, as perguntas permitem explorar um assunto ou aprofundá-lo, descrever processos e fluxos, compreender o passado, analisar, discutir e fazer prospectivas.

A interpretação (do pesquisador) da interpretação dos sujeitos interpelados corresponde àquilo que Anthony Giddens define como dupla hermenêutica, isto é, "a sociologia trata de um universo que já está constituído pelos próprios atores sociais dentro de quadros de significância e o reinterpreta dentro de seus próprios esquemas teóricos" (GIDDENS, 1978, p.171). A hermenêutica consiste, portanto, em uma análise da compreensão dos sentidos e significados atribuídos pelos atores aos processos comunicacionais (verbais ou não) que envolvem uma determinada linguagem. Na pesquisa empírica, a hermenêutica oferece ao pesquisador ferramentas metodológicas para compreender, explicar e contextualizar os sentidos construídos/atribuídos pelos atores sociais em um processo a

11 Entrevistas semiestruturadas combinam perguntas abertas e fechadas, a partir das quais o entrevistado tem a liberdade de discorrer sobre o tema proposto. Este tipo de entrevista tem origem em um roteiro de questões-chave que dão cobertura ao interesse de pesquisa, de maneira que "parte de certos questionamentos básicos, apoiados em teorias e hipóteses que interessam à pesquisa, e que, em seguida, oferecem amplo campo de interrogativas, fruto de novas hipóteses que vão surgindo à medida que se recebem as respostas do informante" (TRIVIÑOS, 1990, p.146).

12 Para Boni e Quaresma, "a entrevista em profundidade é um recurso metodológico que busca, com base em teorias e pressupostos definidos pelo investigador, recolher respostas a partir da experiência subjetiva de uma fonte, selecionada por deter informações que se deseja conhecer" (BONI; QUARESMA, 2005, p.73). 
Elementos materiais e simbólicos na mudança de escala da mobilização dos atingidos por barragens | Gerson Lima de Oliveira

partir do qual o pesquisador traduz a linguagem dos atores à linguagem específica das ciências humanas

Os métodos empregados nesta pesquisa correspondem ao esforço de articulação dos principios da hermenêutica (DILTHEY, 200013; GEERTZ, 1997) com os da fenomenologia (HUSSERL, 1986) ${ }^{14}$ isto é, por um lado visam possibilitar a compreensão dos sentidos tecidos pelos atores e, por outro, visam compreender como estes sentidos são atribuídos pelos mesmos a partir de sua experiência com os processos sociais aqui investigados. Desta maneira, a realização de entrevistas, a análise documental e as observações simples e participante cumprem o objetivo de captar, compreender, traduzir e explicar as gramáticas mobilizadas pelos atores sociais da forma como elas se manifestam em sua experiência. Por isso, para além da realização de entrevistas e da análise documental, as observações simples e participante possibilitam ao pesquisador, em alguma medida, compartilhar - através da aproximação - dos sentidos mobilizados pelos atores sociais em questão. As articulações entre compreensão e experiência manifestam-se a partir dos referenciais teóricos aqui mobilizados, a lembrar, as noções de enquadramento de Benford e Snow (2000) e de gramática e justificação de Boltanski (1991).Veremos adiante como tais procedimentos nos possibilitaram compreender e explicar os mecanismos causais da mobilização dos atingidos por barragens.

\section{Análise dos mecanismos causais identificados}

Veremos agora a análise das informações coletadas na pesquisa de campo. Primou-sepela identificação dos mecanismos que explicam como ocorre a mudança de escala a partir de suas duas dimensões: a expansão organizativa e aamplificação simbólica. Para tanto, levamos em consideração as transformações pelas quais a mobilização e organização dos atingidos por barragens passou ao longo de suas quatro décadas de mobilização. No

\footnotetext{
13 Primeira edição original de 1900.

14 Primeira edição de 1913.
} 
Elementos materiais e simbólicos na mudança de escala da mobilização dos atingidos por barragens | Gerson Lima de Oliveira

esquema abaixo temos a representação gráfica dos principais mecanismos causais da mudança de escala, os quais esmiuçaremos a seguir:

\section{Figura 1 - Mecanismos da Mudança de Escala}

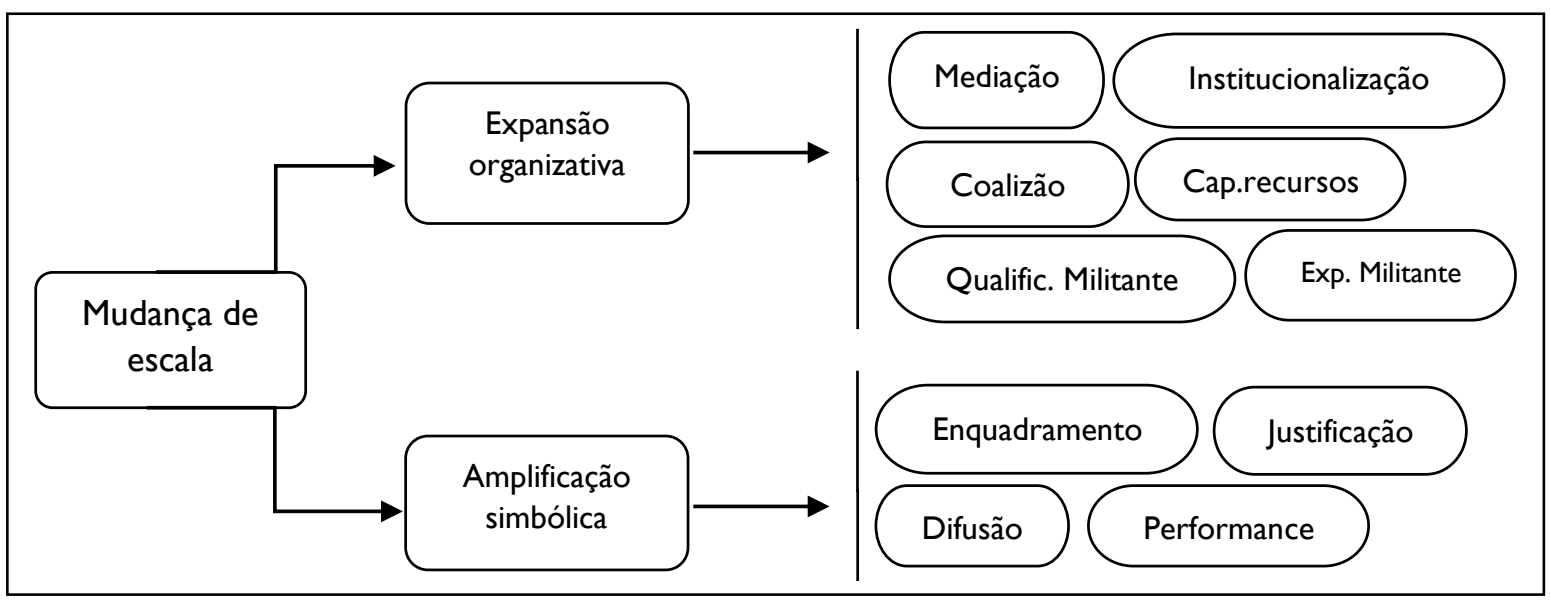

Fonte: Elaboração própria.

A seguir apresentamos definições detalhadas dos mecanismos da mudança de escala a partir das informações obtidas nas entrevistas, das observações de campo e da pesquisa documental:

\section{Mecanismos da Expansão Organizativa: Institucionalização}

Uma vez que os movimentos sociais se consolidam em estruturas mais ou menos sólidas, transformações na forma de organização geralmente ocorrem. As ações passam a exigir estratégias que deem conta da coesão de um número maior de militantes, tornando mais complexo o processo de tomada de decisão, a definição de diretrizes coletivas e aumentando a possibilidade de conformação de disputas entre grupos internos. A organização mais ou menos coordenada de um quadro crescente e plural de militantes requer, muitas vezes, que lideranças centralizem a tomada de decisões. Em consonância a isto, a complexificação dos grupos internos de militantes e a expansão (inclusive geográfica) de um movimento tende a criar distanciamento entre aqueles militantes mais ativos reconhecidos como lideranças e aqueles que não ocupam estas posições e, consequentemente, ficam afastados das principais esferas de tomada de decisão. 
Elementos materiais e simbólicos na mudança de escala da mobilização dos atingidos por barragens | Gerson Lima de Oliveira

Podemos identificar na constituição de organizações sociais a cristalização de relações de interdependência entre indivíduos e grupos nos moldes ilustrados por Norbert Elias (1994) ${ }^{15}$. Diferentemente das abordagens reificadoras, uma análise das interdependências não esvazia a capacidade transformadora de indivíduos relativamente isolados ou de grupos organizados. Estes podem transformar as estruturas quando contam com recursos e condições conjunturais favoráveis para tal, mas o fato de estarem imersos em relações sociais de interdependência (em qualquer instância) pode não somente limitar o alcance de suas intenções, como provocar reações inesperadas que lhes fogem ao controle.

A tese central de alguns autores que são referência nos estudos sobre reprodução estrutural de organizações sociais, dentre eles Piven e Cloward (1979), advoga que ao se cristalizar em estruturas cujo fim seria somente a própria retroalimentação da organização, os movimentos se desvirtuariam de seus propósitos iniciais. Em contraposição a esta ideia, existe a hipótese de que a estruturação que acompanha o crescimento de um movimento social não está relacionada necessariamente à "perda ou desvirtuamento de uma identidade pura e original”, mas sim a uma tendência inerente à transformação do movimento ao longo do tempo, na qual sua expansão quantitativa está diretamente ligada à sua ressignificação qualitativa.

Neste sentido, a mudança de escala dos movimentos geralmente apresenta transformações substanciais na sua forma de organização estrutural decorrente da complexificação de suas relações internas e das relações que passa a constituir com outras organizações coletivas. A expansão geográfica e a decorrente atuação em outros níveis locais e supralocais proporcionada pela mudança de escala e pela difusão dos ideários do movimento requer transformações na maneira de agir de seus militantes e na forma como desencadeiam sua ação coletiva. Se antes o desafio era manter a coesão de um número menor de militantes mais ou menos inexperientes, a mudança de escala exige que a reprodução das ações

\footnotetext{
15 Edição original de 1987.
} 
Elementos materiais e simbólicos na mudança de escala da mobilização dos atingidos por barragens | Gerson Lima de Oliveira

coletivas desencadeadas pelo movimento dependa cada vez mais das alianças que estabelece com outras organizações e da maneira com que é capaz de difundir seus ideários para esferas de discussão mais abrangentes.

Podemos localizar no tempo a institucionalização da organização dos atingidos por barragens logo quando da formação da CRAB, entre os anos de 1978 e 79. A institucionalização do movimento só é possivel a partir da formalização do mesmo por parte dos atingidos e da sua devida consolidação, na qual cumpriram papel preponderante seus apoiadores e outros mediadores. A institucionalização, por exemplo, só é possível quando há recursos materiais e simbólicos disponíveis para tal. A mobilização dos atingidos por barragens é, obviamente, protagonizada pelos mesmos, mas perceberemos através dos relatos coletados nas entrevistas que sua sustentação e ampliação só foi possivel quando outras entidades, como as igrejas católica e luterana, e outros movimentos, como o sindical e o dos sem-terra - já organizados na região de origem do MAB - percebem nos atingidos por barragens um aliado e resolvem apostar neles oferecendo o devido suporte para a sua organização inicial.

Por outro lado, a interferência da mudança de escala - como vimos não se dá somente pela influência de atores externos. As dinâmicas de conflitos e negociações internas são determinantes no fato de um movimento social lograr mudar de escala ou não. No âmbito interno, as disputas e discussões criam tensões representadas, por exemplo, pela definição dos rumos do movimento. Foschiera (2009) relata que a partir da década dos 2000 cria-se dentro do MAB um debate entre a intensificação da luta contra as barragens no local onde elas ocorrem ou o direcionamento dos esforços para a criação de vínculos com a sociedade civil dos grandes centros urbanos, alargando a noção de atingido a fim de se expandir o raio de atuação também para o meio urbano.

Esta segunda estratégia é defendida pelos dirigentes articuladores da atuação do movimento em âmbito nacional e, ao fim, acabaram por vencer a disputa. Para alguns militantes, a mudança de foco nos objetivos do movimento o enfraquece no seu verdadeiro campo de atuação: a "barranca 
Elementos materiais e simbólicos na mudança de escala da mobilização dos atingidos por barragens | Gerson Lima de Oliveira

do rio". Já os defensores das novas diretrizes sustentam que sem aliança com a população urbana e sem o alargamento da noção de atingido, conquistas estruturais e transformações no modelo energético seriam praticamente impossíveis. Veremos mais adiante como esta mudança de rumo implica na transformação discursiva (amplificação simbólica) do movimento a partir de então.

Sem embargo, a partir do momento em que o MAB se fortalece e torna-se um ator de importância regional e, posteriormente, nacional, passa a desempenhar o papel que os movimentos sociais geralmente logram ao mudar de escala: o de influenciar, em maior ou menor grau, a política institucional. Segundo Foschiera (2009), já no final da década de 1980 o MAB e demais movimentos sociais do Alto Uruguai conseguem fazer de suas lideranças populares possiveis lideranças dentro da politica institucional, sobretudo com a eleição de vereadores, prefeitos e figuras com capacidade de influência em chapas políticas no âmbito local. A relação destes movimentos sociais com o Partido dos Trabalhadores é um dos fatores explicativos disto, já que o próprio PT surge como organização partidária cuja finalidade era estabelecer o vinculo entre os movimentos sociais e a esfera institucional. Esta articulação começa nos niveis regionais, mas com a mudança de escala do MAB e a chegada do PT à presidência da república, em 2003, as possibilidades de influência atingem novo patamar, mas que acabaram não se realizando devido aos rumos tomados pelos governos petistas e também pelo poder de seus opositores, as grandes empresas do setor eletroenergético

\section{Mediação}

Como a própria origem etimológica do conceito sugere, a mediação está fundamentalmente ligada ao papel que os indivíduos e grupos mediadores realizam no sentido de intermediarem um determinado processo, servindo como ponte ou suporte para que um determinado indivíduo ou grupo mediado galgue posições estruturais dentro de um contexto. É 
Elementos materiais e simbólicos na mudança de escala da mobilização dos atingidos por barragens | Gerson Lima de Oliveira

interessante pensar o papel da mediação relacionada à definição do conceito de capital social desenvolvido por Bourdieu (1985), por quem é definido como um "agregado dos recursos efetivos ou potenciais ligados à posse de uma rede durável de relações mais ou menos institucionalizadas de conhecimento ou reconhecimento mútuo." Em linhas gerais, para Bourdieu o capital social representa a rede de relações interpessoais (ou interorganizacionais) através das quais os indivíduos e grupos obtêm ganhos materiais e/ou simbólicos. A importância do capital social na teoria bourdieusiana é chave no sentido de ser um dos fatores capazes de explicar a movimentação de indivíduos dentro da estrutura social.

O foco neste momento - inclusive devido ao nosso recorte de pesquisa - não é exaurir a conformação das redes interpessoais dos indivíduos que cumpriram papel de centralidade na mudança de escala da antiga CRAB e atual MAB (tampouco haveria espaço para isso), mas sim demonstrar que o conceito de mediação, atuando com um dos mecanismos capazes de explicar a mudança de escala, desempenha uma função crucial neste processo. E mesmo que o capital social seja fundamentalmente de domínio individual, tanto ele como a mediação podem ser compreendidos também como elementos constituintes das dinâmicas interorganizacionais, visto que estas são, obviamente, compostas por indivíduos. O objetivo aqui, tampouco, é tentar reduzir o papel das organizações à atuação dos indivíduos, mas sim atentar ao caráter de complementariedade entre ambas dimensões. Para os limites desta pesquisa, é suficiente entendermos que a capacidade dos atingidos por barragens e suas lideranças de estabelecerem relações com indivíduos e grupos-chaves será um dos fatores centrais que explicará as origens do processo de mudança de escala do MAB:

Entre as ações mais expressivas desses mediadores, algumas merecem destaque: Quanto à Igreja Católica, a atuação ocorreu através do recrutamento de participantes para o movimento social através de setores da Igreja como a Comissão Pastoral da Terra (CPT), Pastoral da Juventude Rural (PJR) e Ministério Eucarístico, a utilização de estações de rádio como em Concórdia, Marcelino Ramos e Aratiba, até a disponibilidade de pessoal para organização do movimento através dos chamados 'liberados'. A IECLB (Igreja de Confissão Luterana) serviu de canal de ligação entre os atingidos da 
Elementos materiais e simbólicos na mudança de escala da mobilização dos atingidos por barragens | Gerson Lima de Oliveira

bacia do Rio Uruguai com outros locais como Itaipu e Sobradinho, intermediou um apoio financeiro da organização evangélica alemã Brot Fur die Welt (Pão Para o Mundo), além de também 'liberar' pessoal para a organização do movimento social. A FAPES (Faculdade de Erechim), além da pesquisa dos impactos socioeconômicos, importantes para a fundamentação da mobilização e organização em torno do problema, angariou recursos de duas ONGs: da francesa CCFD (Comitê Católico Contra a Fome e pelo Desenvolvimento) e da alemã MISEREOR (Obra Episcopal da Igreja Católica da Alemanha para a Cooperação ao Desenvolvimento). Além destes, é importante a atuação dos Sindicatos de Trabalhadores Rurais (STR), que através de uma perspectiva de 'sindicalismo combativo' estabeleciam uma ligação mais efetiva entre essas instituições e os trabalhadores rurais, além de disponibilizar as estruturas físicas dos sindicatos para a organização do movimento social (ROTHMAN, 1996 apud ROCHA, 2013, p.103).

O excerto acima salienta a relação existente entre institucionalização do MAB e o papel que seus mediadores desempenharam neste processo, sobretudo no que diz respeito à canalização dos recursos materiais, humanos e simbólicos necessários. A estruturação de um campo específico de movimentos sociais do qual o MAB fará parte é o que demonstra primeiramente como o movimento se estrutura e, posteriormente, constitui junto com estes mediadores uma rede de coalizão política, muitas vezes cristalizada na atuação de indivíduos que transitam por vários espaços. Portanto, pode-se concluir que o mecanismo da mediação cumpre um papel crucial no processo de mudança de escala, seja no âmbito simbólico, como no material, de acordo com o que veremos a seguir.

\section{Captação de Recursos}

Um dos principais papéis da mediação é possibilitar o acesso a recursos. Perceberemos aqui que sem o apoio de parceiros e colaboradores é praticamente inviável a um movimento social popular sustentar-se no tempo e expandir seu raio de atuação no espaço. Mesmo após sua consolidação, o MAB - assim como qualquer outro movimento social - necessita angariar recursos para prover suas atividades, atos, campanhas e manifestações. A principal fonte de manutenção do movimento é a contribuição dos próprios 
Elementos materiais e simbólicos na mudança de escala da mobilização dos atingidos por barragens | Gerson Lima de Oliveira

militantes. Entretanto, freqüentemente este acaba sendo um meio insuficiente para o financiamento de campanhas e projetos de grande porte.

Além do apoio direto dos mediadores e colaboradores, uma das maneiras possiveis de se angariar recursos para a realização de projetos no Brasil contemporâneo é a concorrência por editais lançados pelas instâncias governamentais, através dos quais movimentos sociais, ONGs e outras organizações da sociedade civil conseguem financiamento para suas atividades. Estudos recentes demonstram que, ao contrário do que boa parte da literatura comumente advoga (ou espera), no Brasil a relação entre os movimentos sociais e o campo institucional é bastante intensa (MARQUES, 1999; BANASZAK, 2005; SILVA, OLIVEIRA, 2011;). Esta característica é geralmente expressa na trajetória de indivíduos que transitam pela esfera das organizações da sociedade civil e do Estado, representando neste os interesses dos movimentos sociais e estabelecendo vínculos entre os dois campos de atuação.

A concorrência por editais de projetos financiados pelo Estado não está diretamente ligada às relações mediadas por agentes que desempenham este trânsito, mas também é uma das formas a partir das quais dos movimentos sociais conseguem financiamento para suas ações. Exemplo disto é o projeto executado pelo $\mathrm{MAB}$ em reassentamentos de atingidos por barragens que visa o aprendizado e domínio de tecnologias de produção baseadas na agricultura familiar, com o objetivo de promover a autossuficiência - ainda que relativa - dos atingidos em termos de produção alimentar. O projeto de Produção Agroecológica Integrada e Sustentável (PAIS) tem o objetivo de cumprir este papel. A execução da PAIS é uma das formas pela qual o MAB consegue oferecer uma alternativa de produção econômica aos atingidos reassentados, baseada nos princípios políticos e econômicos que regem o movimento, obtendo recursos por meio do vencimento de editais abertos pelo Governo Federal até o ano de 2016.

A participação em projetos fomentados pelo Estado é uma das formas possiveis pelas quais os movimentos sociais captam recursos. Outra alternativa comumente empregada é o estabelecimento de parcerias com 
Elementos materiais e simbólicos na mudança de escala da mobilização dos atingidos por barragens | Gerson Lima de Oliveira

ONGs, fundações, fundos de amparo e instituições nacionais e internacionais. Portanto, na maior parte dos casos, a colaboração financeira dos militantes tão somente mostra-se insuficiente quando o movimento social por eles constituído alcança níveis de ação mais abrangentes. A mudança de escala só se torna viável quando há recursos materiais para tanto, principalmente através da constituição de redes de apoio mútuo.

\section{Alinhamento e formação de redes de coalizão}

A constituição de redes e parcerias com outros movimentos sociais é bastante eficaz na captação recursos, mas é também importante, sobretudo, na conformação de coalizões que fortalecem os movimentos sociais enquanto atores politicos. Se, isoladamente, o confronto com opositores geralmente é desfavorável aos movimentos sociais, a formação de alianças politicas com outros movimentos - de reivindicações distintas, mas pertencentes ao mesmo campo político-ideológico - tem como objetivo fortalecer os mesmos, sobretudo quando adotam principios politicos mais abrangentes que superam suas reivindicações mais específicas. Franklin Ramírez Gallegos (2015) sustenta que a capacidade de os movimentos sociais transformarem seus problemas "específicos" em problemas "públicos" possibilita que ganhem força para pressionar o Estado tendo em vista o atendimento de suas demandas. A consolidação de um bloco político envolvendo a conjunção de movimentos sociais e seus representantes dentro do Estado tende a acelerar este processo. Desta forma, a consolidação de uma coalização politica permite aos movimentos sociais se fortalecerem no sentido de confrontar e, até mesmo, ocupar a esfera pela qual nas sociedades modernas as transformações políticas tendem a ocorrer: o Estado.

A trajetória do $\mathrm{MAB}$, neste sentido, assim como a de uma série de outros movimentos sociais contemporâneos seus é marcada por esta característica. Muitos deles compartilham, inclusive, das mesmas origens que é o da influência dos setores médio-populares brasileiros das décadas de 1970 e 80, mediados por setores progressistas das igrejas católica e 
Elementos materiais e simbólicos na mudança de escala da mobilização dos atingidos por barragens | Gerson Lima de Oliveira

luterana, pelo movimento sindical que emergia quando o regime civil-militar dava sinais de enfraquecimento, pelos novos partidos políticos do campo da esquerda que (re)surgiam diante da crescente debilidade de sustentação no poder dos militares, pela influência de parte da comunidade acadêmica engajada, entre outros agentes.

A formação de uma coalizão política desta natureza teve impacto não somente na capacidade material de organização de movimentos sociais como MAB, Movimentos dos Trabalhadores Rurais Sem-Terra (MST) e Movimento dos Pequenos Agricultores (MPA), como principalmente na construção de uma identidade coletiva que caracteriza este campo de maneira peculiar: a defesa da união dos movimentos do campo e da cidade; a construção de uma identidade nacional brasileira baseada na imagem popular dos indivíduos impactados pelos efeitos da desigualdade político-econômica gerada pelo capitalismo; a imagem de um "povo de Deus"- influência do campo político religioso, principalmente da Teologia da Libertação -, que sofre e luta em que busca um mundo melhor baseado na solidariedade, na superação das desigualdades sociais e do capitalismo.

A construção desta identidade coletiva influenciou diretamente a constituição e transformação identitária dos movimentos sociais e outras entidades que compõem esta coalizão, provocando modificações, inclusive, nas suas reivindicações. No caso do MAB, fica claro como as distintas parcerias formadas ao longo do tempo influenciaram diretamente a transformação discursiva do movimento e inclusive suas demandas. A formação de uma coalizão pode ser eficaz no fortalecimento mútuo através do compartilhamento de material humano, de recursos materiais, na construção de uma identidade coletiva e na formação de um ator político coletivo que possibilita aos seus integrantes pleitear reivindicações mais abrangentes às que tinham originalmente, assim como maior poderio para pressionar, confrontar e até mesmo ocupar a esfera política estatal.

\section{Qualificação dos quadros militantes}


Elementos materiais e simbólicos na mudança de escala da mobilização dos atingidos por barragens | Gerson Lima de Oliveira

Um outro mecanismo importante diretamente relacionado à formação de coalizões políticas é a qualificação dos quadros militantes. À medida que o movimento muda de escala e passa a mobilizar discursos mais complexos e abrangentes é exigido de seus militantes, sobretudo de suas lideranças, a capacidade de manejo de discursos e conhecimentos que deem conta da atuação em novas arenas de disputa. No caso dos atingidos por barragens isto acontece quando o movimento passa a discutir seus problemas como um fenômeno diretamente ligado à atuação dos agentes que exploram recursos energéticos no âmbito da economia capitalista. Para discutir com propriedade estes aspectos, militantes dirigentes e militantes de base são levados a estudarem, compreenderem e explicarem o próprio sistema capitalista e suas implicações.

Quando passam a propor um novo modelo energético distinto ao modelo que opera sob os ditames do capitalismo, são levados a discutir tecnicamente o papel da produção energética nas sociedades modernas, instigando-os a dominarem áreas do conhecimento técnico-científico que os permitam debater com propriedade aquilo que os afeta e aquilo que propõem como alternativa nas arenas de poder, fundamentalmente legitimadas e obedientes à linguagem dos saberes acadêmicos. Como os atingidos por barragens são em sua grande maioria formados por parcela da população alijadas dos centros de poder e suas linguagens, quando sua mobilização passa a mudar de escala são então desafiados a dominarem os saberes socialmente reconhecidos (centralmente, o técnico-científico) para poderem confrontar seus opositores com menor desvantagem.

A mobilidade proporcionada pela capacidade de manejo de saberes diversificados é possibilitada, em grande medida, pelo papel dos mediadores que compõem ou simplesmente se alinham à coalizão de movimentos sociais. No caso dos atingidos por barragens, este caminho foi traçado a partir da colaboração de agentes acadêmicos apoiadores da causa do movimento e por outros mediadores que já transitavam pelo campo acadêmico e desta forma abrem as portas da academia à parcela dos 
Elementos materiais e simbólicos na mudança de escala da mobilização dos atingidos por barragens | Gerson Lima de Oliveira

atingidos por barragens. A mudança de escala e a amplificação simbólica foram possibilitadas também a partir da capacidade de parte dos atingidos pelo menos de suas lideranças - de discutir teoria politica e relacioná-la às condições dos atingidos por barragens, discutindo em seguida as implicações e consequências técnicas de se defender o atual modelo energético ou a alternativa proposta pelo MAB.

No entendimento de como determinados mecanismos contribuem para a mudança de escala, podemos perceber que a qualificação militante estabelece uma relação importante entre a expansão territorial e a amplificação simbólica, pois ao causar uma transformação discursiva (que se traduz na prática) possibilita a determinadas lideranças dos atingidos manejarem discursos que os autoriza a enfrentar seus opositores em outras arenas, assim como transitar por outros espaços como campo político institucional.

\section{Exportação militante}

A qualificação de parte dos segmentos atingidos por barragens está relacionada a um outro mecanismo da mudança de escala: a expansão territorial, dada sobretudo através da "exportação militante". Vimos que o processo de institucionalização do movimento, juntamente à capacidade de captar recursos são mecanismos que implicam na expansão territorial do movimento, já que proporcionam condições materiais para tal. Todavia, um movimento social não logra expandir seu raio de atuação somente com recursos materiais. A capacidade de articulação politica e social que sustentam a mobilização é um dos pontos nevrálgicos deste processo.

A expansão territorial do MAB do Sul em direção ao Norte do Brasil se deu basicamente através da "exportação" do know how de seus quadros militantes formados no Sul e Sudeste para outras regiões do país. Em alguns casos, a estruturação do movimento nos moldes sulistas foi bem-sucedida na difusão das lógicas organizativas à outras regiões; em outros casos, esbarrou nas já consolidadas formas de organização de outros grupos populacionais, sobretudo indígenas do Norte do país, que não compartilham 
Elementos materiais e simbólicos na mudança de escala da mobilização dos atingidos por barragens | Gerson Lima de Oliveira

dos mesmos princípios e objetivos. Outrossim, após a formalização do MAB em 1991, a estratégia de expandir o movimento com o objetivo de unificar a luta das distintas populações atingidas por barragens segue sendo uma estratégia central do movimento:

As lideranças locais geralmente são encaminhadas para os cursos de formação mencionados acima e a partir de sua experiência prática somada à formação técnico-teórica, recebem a missão de organizar os atingidos por barragens onde a mobilização social é ainda incipiente. Portanto, a expansão territorial - diretamente relacionado à mudança de escala - dá-se, sobretudo, através do mecanismo da exportação militante, que consiste em levar lideranças e quadros militantes experientes à outras regiões, tentando cumprir o papel que o MAB se propõe de unificar a mobilização dos atingidos por barragens em território nacional. Entretanto, é preciso destacar que a exportação militante não é a única forma de expansão da organização do MAB. A aposta na formação de lideranças locais se dá concomitantemente a este processo, sendo inclusive um dos efeitos deste intercâmbio.

\section{Mecanismos da Amplificação Simbólica: Enquadramento e Justificação}

Vimos na introdução que o processo de enquadramento consiste na seleção de alguns aspectos da realidade percebida e traduzida a um determinado contexto de acordo com as percepções compartilhadas pelos indivíduos e pelos interesses em jogo entre eles. Como já destacado por Benford e Snow (2000), o framing process consiste em uma espécie de batalha interpretativa acerca de uma determinada questão ou problema social. Enquadrar a realidade implica, desta forma, na tradução e na construção de uma versão baseada em aspectos da realidade geralmente selecionados sob influência dos sentimentos e impressões que os efeitos de determinado fenômeno social provocam nos indivíduos, pela sua capacidade de explicação e pela influência da sua posição estrutural (de onde se vê e fala). Ainda que o enquadramento seja a construção de uma versão, sua sustentação é proporcional à sua correspondência com os aspectos factuais 
Elementos materiais e simbólicos na mudança de escala da mobilização dos atingidos por barragens | Gerson Lima de Oliveira

da realidade, pelo grau de veracidade e valor compartilhado social e contextualmente.

Por mais que os impactos socioambientais gerados pela construção de barragens sejam impactos por si só (no sentido de que são reais por serem factuais), eles só serão considerados um problema de fato se assim forem entendidos socialmente e se lhes forem dadas a devida importância e relevância. A construção de barragens é, desde sempre, um problema que afeta diretamente as populações atingidas. Entretanto, só entra na pauta política na medida em que os atingidos por barragens se mobilizam e enquadram este acontecimento como um problema social, apresentando à sociedade uma versão oposta à de que a construção de barragens simboliza integralmente o desenvolvimento, que a hidroeletricidade corresponde à produção de energia limpa ou de que o deslocamento compulsório de populações seja um preço necessário a ser pago para se atingir o progresso.

Este posicionamento é apresentado, obviamente, em decorrência da posição estrutural que os atingidos ocupam diante da construção de uma barragem. Os efeitos materiais e simbólicos produzidos pelo acontecimento os leva a confrontar os enquadramentos vigentes e, para tanto, é preciso que mobilizem justificativas para o seu posicionamento que os permita conquistar o apoio de outros segmentos sociais no confronto com seus opositores. Como também vimos anteriormente, Boltanski (1991) chama justificação o processo pelo qual indivíduos mobilizam sensos de justiça a partir de determinadas gramáticas através das quais apresentam suas questões recorrendo a ordens de grandeza que as relacionam a processos mais ou menos generalizadores, pelos quais visam a legitimação de seus posicionamentos de acordo com preceitos morais valorizados dentro de um contexto.

Em outras palavras, a legitimidade de um posicionamento acerca da realidade é conquistada na medida em que os indivíduos conseguem conectar seus problemas particulares a ordens de grandeza capazes de aproximar moralmente seus dilemas aos de outros indivíduos através de 
Elementos materiais e simbólicos na mudança de escala da mobilização dos atingidos por barragens | Gerson Lima de Oliveira

uma linguagem que os aproxime e os permita compartilhar compreensões, entendimentos, sensações e princípios ético-morais acerca da realidade.

No caso dos atingidos, isto se dá na demonstração, comprovação e também na construção de um problema social representado pela construção de barragens, que, ao contrário do que a maior parte da população possa pensar, é também um acontecimento que provoca mazelas. A batalha dos atingidos contra seus opositores se dá, então, também na disputa sobre o que vale a pena afinal: desenvolvimento a qualquer custo ou construção de um novo modelo que não fira o modo de vida dos atingidos? Para tanto, eles necessitam serem ouvidos pelo restante da sociedade de maneira a transformar o seu problema específico em um dilema moral também para aqueles grupos sociais que não compartilham da sua posição estrutural em relação ao acontecimento.

$\mathrm{Na}$ medida em que os atingidos vão percebendo que o seu problema específico está conectado a processos políticos e econômicos mais abrangentes e ao passo em que sua mobilização vai ganhando força e volume, faz-se necessário que dialoguem com outros setores da sociedade para manter e ampliar sua capacidade de ação, sobretudo quando o movimento muda de escala e passa a confrontar opositores maiores, assim como a incorporar ao discurso questões sociais mais abrangentes e objetivos mais complexos. O grau de generalidade que vai sendo paulatinamente incorporado ao discurso do MAB está diretamente relacionado à capacidade de enquadrar a realidade e de referir-se a ordens de grandeza que dialogam com um universo cada vez maior de reivindicações e, conseqüentemente, de interesses compartilhados com outros grupos sociais que não são diretamente atingidos pelas barragens, mas que podem comungar dos mesmos princípios ético-morais defendidos pelo MAB.

A costura de discursos que tramam um enquadramento também tem a capacidade de [re]criar a realidade, pois instigam formas de comportamento baseadas em certas gramáticas a partir das quais - em suas atitudes e ações - os indivíduos vão produzindo efeitos reais no mundo. É 
Elementos materiais e simbólicos na mudança de escala da mobilização dos atingidos por barragens | Gerson Lima de Oliveira

desta forma, então, que o MAB vai agregando à luta dos atingidos por barragens pautas mais abrantes como o ambientalismo, socialismo e até o feminismo. Com o passar do tempo e conforme as transformações discursivas de enquadramento que a sociedade vai [re]criando, as próprias demandas do movimento vão se modificando. Os exemplos de principal destaques são justamente a causa ambientalista, que passa a ser incorporada na agenda politica internacional de forma cada vez mais presente a partir das décadas de 1980 e 90 - o impacto da Eco 92 realizada do Rio de Janeiro tem representatividade preponderante no Brasil neste sentido - e o caso do feminismo, que a partir dos anos 2000 - muito sob influência do papel que as novas tecnologias de informação ligadas à Internet tem desempenhado-, passa a ocupar um lugar de destaque dentro do debate político, sobretudo no âmbito dos movimentos sociais ligados à esquerda.

O alargamento do enquadramento das reivindicações dos atingidos por barragens primeiramente se dá em direção às questões políticoeconômicas de classe e à compreensão de que o problema que os atinge está diretamente ligado aos efeitos do capitalismo. Posteriormente, passa à incorporação de questões ambientais e à noção de que os impactos gerados não ferem somente os direitos humanos, mas também à natureza (e, consequentemente, os seres humanos, pois também são parte da natureza). Mais recentemente, e agora o alargamento/incorporação de outras pautas reivindicatórias, como a conexão da questão dos atingidos à luta pela garantia de direitos às mulheres, na qual o papel das mulheres atingidas passa a ser cada vez mais enfatizado dentro do movimento. Uma outra estratégia utilizada pelo MAB mais recentemente, é a de pautar muitas de suas ações na ideia de que não somente as populações da "barranca do rio" que são atingidas pelas barragens, mas que todo o processo de exploração capitalista da produção energética termina por tornamos todos atingidos, uma vez que o preço da energia alto para os pobres e, ainda assim, não chega a todas as localidades do país, o que seria consequência do fato de a produção energética não ser pautada por um viés público. 
Elementos materiais e simbólicos na mudança de escala da mobilização dos atingidos por barragens | Gerson Lima de Oliveira

Dessa forma, conforme a mudança de escala é construída, os movimentos sociais tendem a termaior capacidade de difundir e amplificar suas demandas relacionando-as a pautas diversas, pelas quais tornam mais complexas suas reivindicações iniciais. Isto se dá pela "tradução" das gramáticas por eles mobilizadas, logo, servindo de ponte entre seu caso específico e questões mais abrangentes, servindo como base para a "universalização" de suas demandas.

\section{Performance}

Um mecanismo capaz de expressar de maneira bastante eficiente as gramáticas mobilizadas pelo movimento é a performance. Característica marcante dos movimentos sociais, a ação performática tem por objetivo expressar sensos de justiça e ordens de grandeza através do reforço de determinadas características que visam enfatizar elementos da identidade coletiva pela qual os movimentos sociais procuram definir-se publicamente. A identidade coletiva é, então, comumente expressada através de atos públicos que geralmente visam tocar a subjetividade daqueles a quem pretende-se comunicar. No caso dos atingidos por barragens, alguns elementos simbólicos da identidade coletiva já foram citados anteriormente, como a mobilização de representações sociais acerca do que definiria o povo (atingido) e seu sofrimento.

Isto se dá através do reforço da imagem de que os atingidos são trabalhadores e trabalhadoras das classes populares, já assolados pelas consequências das desigualdades socioeconômicas e que são, adicionalmente, afetados pela construção de barragens, dificultando ainda mais condições de vida que já não eram fáceis. Neste sentido, as ações performáticas visam comunicar à sociedade uma série de características vinculadas à imagem de um tipo ideal de atingido como representação do povo que se mobiliza contra as injustiças, luta por seus direitos e por um futuro melhor para todos. Para tanto, o papel da performance é o de expressar elementos morais e, desta forma, provocar simbolicamente o 
Elementos materiais e simbólicos na mudança de escala da mobilização dos atingidos por barragens | Gerson Lima de Oliveira

público-alvo a compreender as razões pelas quais a mobilização acontece, por que ela é justa, necessária e merecida de ser apoiada.

$\mathrm{Na}$ pesquisa de campo realizada pôde-se observar o papel, inclusive ritualístico, que as atividades de performance - denominadas pelos movimentos sociais de "mística" - cumprem como elemento de coesão do grupo e comunicação externa. Tratam-se de atividades geralmente dramatizadas, através das quais os atingidos expressam sentidos e valores que reforçam a identidade coletiva internamente e procuram sensibilizar àqueles aos quais desejam apoio ou simpatia. De maneira geral, as atividades de protesto no espaço público alinham discurso político e performance como forma de conquista de legitimidade.

Rafael Bellan Souza em uma pesquisa sobre o papel da mística no MST sustenta que "a convicção na luta recebe o combustivel dos valores e das contribuições ideológicas formatadas no rito (...) onde o fator emotivo encontra-se na perspectiva estética, que re-encanta o mundo por meio da criação de projetos e alternativas ao modelo vigente, em um formato diferente da ciência" (2012, p.73). É em ações de performance como a mística que se percebe a presença e importância destacada por Jasper, Goodwin, Polletta (2001) e Cefaï (2009) dos elementos emotivos como importantes mecanismos de reforço e renovação das mobilizações.

A experiência de ser impactado negativamente por um acontecimento pode despertar uma série de sentimentos coletivos, dentre eles a revolta e indignação que tendem a ser combustiveis importantes para manterem os indivíduos ativos em atividades de militância. A identificação coletiva dada pelo compartilhamento de sensos de [in]justiça, assim como o compartilhamento de um projeto futuro baseado na resolução do problema e na defesa de transformações sociais mais profundas são elementos fundamentais pelos quais pode-se entender como os movimentos sociais ao mesmo tempo mantêm-se coesos, expõem publicamente seus posicionamentos e ao mesmo tempo produzem enquadramentos da realidade. A performance cumpre este papel de maneira distinta, mas não menos importante que a articulação técnica de princípios, preceitos e ideias. 
Elementos materiais e simbólicos na mudança de escala da mobilização dos atingidos por barragens | Gerson Lima de Oliveira

\section{Difusão}

A difusão desempenha o papel tanto do espraiamento das ideias defendidas pelos movimentos sociais, quanto da manutenção da coesão interna, na medida em que a definição de um conjunto de ideias a serem propagadas pela militância também reforça elementos da identidade coletiva do grupo.Ao longa de sua história, o MAB adotou distintos meios de comunicação como forma de difundir o movimento entre os atingidos por barragens em seus locais de mobilização e também para o restante da sociedade. Nas décadas de 1980 e 90, além dos atos públicos, as principais formas de comunicação utilizadas pelo MAB eram a publicação de jornais, panfletos informativos e a realização de programas em espaços cedidos nas rádios locais, que, em localidades mais isoladas, continuam sendo o principal veículo de informação sobre a situação das barragens, de prognósticos sobre possíveis impactos para populações potencialmente atingidas e também como forma de difusão dos posicionamentos do movimento. A partir dos anos 2000, sobretudo, passa a ganhar espaço a difusão através das mídias virtuais alocadas na Internet, tais como sítio oficial e redes sociais.

Uma das consequências da mudança de escala é a profissionalização dos movimentos sociais no tratamento de sua imagem pública e no domínio de ferramentas que possibilitam a sua difusão. No caso do MAB, há parcela de sua militância formada academicamente em jornalismo e outros cursos que possibilitam o domínio qualificado destas ferramentas. São os militantes responsáveis pela comunicação do movimento que geralmente produzem materiais multimídia como vídeos e documentários divulgados em seu sítio oficial e nas redes sociais.

Com o advento e popularização do uso da Internet, as ferramentas virtuais passam a ganhar cada vez mais espaço como meio de comunicação através do qual os movimentos sociais difundem seus ideários. Em muitos casos, já é a principal ferramenta de divulgação somando-se aos meios mais 
Elementos materiais e simbólicos na mudança de escala da mobilização dos atingidos por barragens | Gerson Lima de Oliveira

tradicionais que continuam sendo utilizados como jornais, cartilhas e do rádio. Se todas estas ferramentas possibilitam a potencialização da capacidade de difusão dos movimentos sociais, entretanto, elas não substituem - e nem é esse o seu propósito - a importância da realização de atos públicos, intervenções, encontros, reuniões e congressos.

\section{Considerações Finais}

Nesta pesquisa traçamos uma explicação causal do processo de mudança de escala das organizações de movimento social, tendo como exemplo empírico o caso dos atingidos por barragens na bacia do rio Uruguai. A principal motivação foi a exploração dos mecanismos que explicam o crescimento e difusão de uma mobilização social e os mecanismos pelos quais os indivíduos reunidos em um movimento social enquadram a realidade, tecem sensos de justiça e relacionam suas demandas específicas a questões sociais mais abrangentes. A contribuição a que se propõe este estudo é a de propor a realização de pesquisas que se atenham menos à constatação e descrição de processos sociais e mais à tentativa de explicação de como e porque estes se desencadeiam.

Avaliando o processo de mudança de escala do MAB, podemos concluir que este possibilitou aos atingidos por barragens ampliar consideravelmente seu grau de atuação e influência tendo em vista a resolução dos problemas que os fazem atingidos. Estes problemas estão muito longe de serem resolvidos, entretanto, a consolidação de um ator coletivo possibilitou aos atingidos uma forma expressiva de empoderamento para, pelo menos, resistir aos impactos com maior potência. Todavia, a mudança de escala não se consuma sem provocar tensões na organização coletiva. Isto significa que há um preço a ser pago pela mudança de escala e este se manifesta na complexificação das relações internas e externas do movimento.

Sobre a institucionalização percebe-se que da mesma forma que fortalece a ação coletiva, diversifica o número de papéis e funções necessárias para a manutenção do movimento o que, geralmente - e com o 
Elementos materiais e simbólicos na mudança de escala da mobilização dos atingidos por barragens | Gerson Lima de Oliveira

MAB não foi diferente -, pode intensificar tensões internas como as diferenças entre lideranças e militantes de base. Neste mesmo sentido, a especialização militante possibilita ao movimento ingressar em novas arenas e disputá-las com maior propriedade, da mesma maneira em que contribui para o aumento das diferenças internas, visto que alguns militantes passam a levar as discussões para um determinado nível, enquanto as exigências do embate local no qual "as bases" estão envolvidas podem demandar interesses mais "pragmáticos". Isto ficou evidente quando do Encontro Nacional, debates foram realizados sobre os rumos do movimento e pôde-se detectar a manifestação de duas posições que se confrontavam: a de seguir alargando os marcos de discussão teórico-conceitual do movimento junto à sociedade e o de concentrar esforços no pragmatismo do confronto às barragens. Da mesma forma, como discutimos anteriormente, a exportação militante consiste em um dos principais mecanismos de expansão do movimento, da mesma forma em que o trânsito de lideranças especializadas pode gerar conflitos com lideranças locais mais tradicionais ou com grupos sociais que não compartilham integralmente dos princípios do movimento, como no caso das populações indígenas, por exemplo. Isto é, a mudança de escala possibilita ao movimento atuar com maior força, mas exige da coletividade um esforço muito maior de manutenção da mesma.

Fazendo uma leitura e uma avaliação desta complexidade a partir de nossas referências teóricas, percebeu-se que a mudança de escala também implica numa complexificação das causalidades. A ampliação das diferenças internas provocadas pela expansão e diversificação dos quadros militantes provoca uma transformação nos níveis de causalidade a partir dos quais "bases" e lideranças atuam ea manifestação de diferenças internasé um exemplo disto. Enquanto as lideranças e militantes especializados trabalham em nível macroestrutural, ou seja, discutem o movimento de forma abrangente, isto exige deles que trabalhem com um nivel de causalidade macro, isto é, de que os impactos gerados sobre os atingidos provêm de articulações do capitalismo internacional e que, portanto, é preciso que o 
Elementos materiais e simbólicos na mudança de escala da mobilização dos atingidos por barragens | Gerson Lima de Oliveira

movimento discuta, debata e alargue seus enquadramentos e justificações tendo por objetivo mobilizar a sociedade como um todo. Por outro lado, as articulações de base podem estar mais restritas ao plano microssocial e que, por isso, dedicar muito esforço em elaborações teóricas poderia desviar o movimento de seu principal objetivo: a luta contra as barragens e contra seus modos de viver daquele rio e naquele ambiente. O nível de causalidade micro poderia conferir à atuação das bases um pragmatismo de natureza distinta à práxis das lideranças, configurando uma nova complexidade da mudança de escala: o desafio posto à mobilização coletiva pelo encontro com niveis diversificados de causalidade. Neste caso, a experiência de cada militante (ou grupos deles) com o movimento e com sua atuação no mesmo é balizadora de seu posicionamento, o que explica os conflitos internos expostos.

Por outro lado, a ênfase que demos à amplificação simbólica teve por objetivo evidenciar a conjunção de elementos emocionais e estratégicos que nos possibilitam questionar a clássica dicotomia entre emotividade e racionalidade no campo das ciências (sociais). A análise dos elementos emotivos envolvidos no processo de engajamento pode ser chave na compreensão de como militantes de movimentos sociais - a partir de suas experiências - ligam suas demandas específicas a grandes transformações sociais.

O que as pesquisas citadas neste trabalho demonstram é que o papel do caráter emotivo na construção dos sentidos da condição militante é uma dimensão importante nos processos de escolha e motivação para que as pessoas se mobilizem e permaneçam engajadas em lutas que dão sentido a suas vidas, sobretudo no que diz respeito à manutenção dos seus modos de vida. Inventariar os elementos emotivos presentes no desencadeamento da mobilização é importante também para entendermos como os agentes relacionam a carga emotiva de sua experiência envolvida no processo de engajamento com a elaboração de sensos de justiça, como o questionamento do modelo de desenvolvimento hegemônico na defesa de seus modos de vida e do ambiente onde eles são vividos. Explorar tais elementos é útil para 
Elementos materiais e simbólicos na mudança de escala da mobilização dos atingidos por barragens | Gerson Lima de Oliveira

entendermos como os indivíduos transformam uma multiplicidade de indignações individuais acerca de um problema social (a construção de barragens, por exemplo) em mobilização coletiva que relaciona uma série de sensos de [in]justiças com lutas concretas por transformações estruturais.

Benford (1997) admite que nos estudos sobre enquadramentos interpretativos a dimensão emotiva ainda é pouco explorada. Segundo o autor, estes elementos podem ser chave na captação de sentidos e mecanismos que explicam a deflagração de ações coletivas contestatórias. Esta tarefa exigiria que se equilibrasse a balança entre emotividade e racionalidade, evidenciando a importância do caráter emotivo nos processos de engajamento como um passo importante na construção de análises mais complexas e precisas sobre os movimentos sociais, não só calcadas no caráter estratégico das mesmas. Entretanto, é preciso cautela para não se cair estritamente para o lado oposto: dar margem a abordagens que tratam os sujeitos como obedientes a dimensões supostamente inconscientes dos desejos, como se o suposto desvelamento de determinadas estruturas mentais pudesse explicar as ações dos sujeitos sob o controverso argumento de que estes "não sabem bem o que fazem e por que o fazem" e simplesmente reproduzem estruturas. A apresentação da amplificação simbólica e da expansão organizativa como parte de um mesmo processo teve por objetivo equilibrar esta balança.

Assim sendo, esperamos contribuir com a possibilidade de um modelo explicativo que se some no âmbito da sociologia dos movimentos sociais a respeito de como as mobilizações sociais podem, primeiramente, sustentar-se e, logo, ampliar-se e difundir-se. Isto, apresentando um tipo de abordagem que rompa com algumas dicotomias como "material X simbólico" e "racional X emotivo". O caso escolhido para ser analisado nos parece frutífero, a partir do qual pudemos discutir uma série de questões teóricas e empíricas, tais como as que aqui apresentamos, mas que não estão, obviamente, esgotadas. Esperamos, desta forma, que o esforço empregado aqui contribua para o avanço e prosseguimento deste debate, sobretudo no 
Elementos materiais e simbólicos na mudança de escala da mobilização dos atingidos por barragens | Gerson Lima de Oliveira

que diz respeito às controvérsias envolvendo noções conflitantes sobre desenvolvimento, ambiente e modos de vida.

\section{Referências Bibliográficas}

ARCHER, Margaret. Realist social theory: themorphogenetic approach. Cambridge. UK: University Press, 1995.

ARCHER, Margaret. Criticalrealism: essentialreadings. Londres: Routledge, 1998.

BANASZAK, Lee Ann (2005). Inside and outside the state: movement insides status, tactics and public policy achievements. In: MEYER; DAVID; JENNESS; INGRAM (eds.). Routing the opposition: social movements, public policy, and democracy. Minneapolis: Universityof Minnesota Press., p.149-176.

BENFORD, Robert. Aninsider's critique ofthe social movementframing perspective. Sociologicalinquiry, v.67, p. 409-430, 1997.

BENFORD, Robert; SNOW, David. A framim process and social movements: an overview and assessment. Annual Review of Sociology, n.26, p.611$639,2000$.

BENINCÁ, Dirceu. Energia \& Cidadania - a luta dos atingidos por barragens. São Paulo: Cortez, 2011.

BHASKHAR, Roy. Scientific realisman dhuma nemancipation. Londres: Verso, 1986.

BHASKHAR, Roy. Reclaiming reality: a critical introduction to contemporary philosophy. Londres: Verso, 1989.

BOLTANSKI, Luc; THÉVENOT, Laurent. De la justification: les économies de la grandeur. Paris: Gallimard, 1991.

BOLTANSKI, Luc; CHIAPELLO, Éve. O novo espirito do capitalismo. São Paulo: Martins Fontes, 2009 [ $1^{a}$ ed. 1999].

BONI, Valdete; QUARESMA, Sílvia. Aprendendo a entrevistar: como fazer entrevistas em Ciências Sociais. Em Tese, Florianópolis, v. 2, n. 1, p.68-80, jan.-jul, 2005.

BOURDIEU, Pierre. The formsof capital. In: RICHARDSON, J. (Comp.). Handbookoftheoryandresearch for thesociologyofeducation. New York: Greenwood, 1985. 
Elementos materiais e simbólicos na mudança de escala da mobilização dos atingidos por barragens | Gerson Lima de Oliveira

CEFAII, Daniel. Como nos mobilizamos? A contribuição de uma abordagem pragmatista para a sociologia da ação coletiva. Dilemas: Revista de Estudos de Conflito e Controle Social, v. 2, n. 4, p. 11-48, 2009.

DILTHEY, Wilhelm. Introdução às Ciências Humanas. São Paulo: Forense, 2010.

ELIAS, Norbert. A sociedade dos indivíduos. Rio de Janeiro: Jorge Zahar Ed., 1994.

FOSCHIERA, Atamis Antônio. Da barranca do rio para a periferia dos centros urbanos: a trajetória do Movimento dos Atingidos por Barragens face às políticas do setor elétrico no Brasil. Tese de Doutorado. Presidente Prudente: UNESP, 2009.

GALlEGOS, Franklin R. Political Change, State Autonomy, and PostNeoliberalism in Ecuador, 2007-2012. Latin American Perspectives, 2015.

GEERTZ, Clifford. O saber local. Petrópolis: Vozes, 1997.

GIDDENS, Anthony. Novas regras do método sociológico. Rio de janeiro: Zahar Editores, 1978.

HÜFFNER, Anelise; ENGEL, Bruna Cristina (orgs). Grandes e pequenas centrais hidrelétricas na bacia do Rio Uruguai: Guias para ONGs e movimentos sociais. Porto Alegre: Amigos da Terra - NatBrasil, 2011.

HUSSERL, Edmund. A ideia de fenomenologia. Lisboa: Edições 70, 1986.

IBARRA, Peter; KITSUSE, John. Vernacular constituents of moral discourse: an interactionist proposal for the study of social problems. In: HOLSTEIN, James \& MILLER, Gale (org). Reconsidering social constructionism: debates in social problems theory. Transaction Publishers: New Brunswick, New Jersey, 1993.

JASPER, James; GOODWIN, Jeff; POLLETTA, Francesca. Passionate politics. Chicago: University of Chicago Press, 2001

MARQUES, Eduardo. Redes sociais e instituições na construção do Estado e da sua permeabilidade. Revista Brasileira de Ciências Sociais, vol.14, $\mathrm{n}^{\circ} 41, \mathrm{p} .45-67.1999$

McADAM, Doug, TARROW, Sidney, TILLY, Charles. Dynamics of Contention. New York and Cambridge: Cambridge University Press, 2001.

MACHAMER, Peter; DARDEN, Lindley; CRAVER, Carl F.. Thinking about Mechanisms. Philosophy of Science, Vol. 67, No. 1, pp. 1-25, March/2000. 
Elementos materiais e simbólicos na mudança de escala da mobilização dos atingidos por barragens | Gerson Lima de Oliveira

PIVEN, Frances Fox; CLOWARD, Richard A. Poor people's movements: why they succeed, how they fail. New York: Vintage Books, 1979.

ROCHA, Huberto J. Relações de poder na instalação de hidrelétricas. Passo Fundo: UPF Editora, 2013.

ROCHA, Huberto J. O controle do espaço-tempo nos processos de instalação de hidrelétricas. Tempo Social, São Paulo, v. 26, n. 1, p. 259-280, junho 2014.

ROTHMAN, Franklin D. A emergência do movimento dos atingidos pelas barragens da bacia do Rio Uruguai, 1979-1983. In: NAVARRO, Zander (org.), Politica, protesto e cidadania no campo.Porto Alegre: Editora da Universidade (UFRGS), 1996.

SILVA, Marcelo K; OLIVEIRA, Gerson de Lima. A face oculta(da) dos movimentos sociais: trânsito institucional e intersecção Estado-Movimento uma análise do movimento de Economia Solidária no Rio Grande do Sul. Sociologias, v. 13, n. 28, p. 86-125, 2011.

SOUZA, Rafael Bellan Rodrigues de. A mistica do MST: mediação da práxis formadora de sujeitos históricos. 2012. $147 \mathrm{f}$. Tese de doutorado. Universidade Estadual Paulista Júlio de Mesquita Filho, Faculdade de Ciências e Letras (Campus de Araraquara), 2012.

TARROW, Sidney; McADAM, Doug. Scale shift in transnational contention. In: DELLA PORTA, Donatella; TARROW, Sidney (eds). Transnational protest and global activism. Nova Iorque: Rowman and Little field Publishers, 2005.

TRIVIÑOS, Augusto. Introdução à pesquisa em ciências sociais: a pesquisa qualitativa em educação. São Paulo: Atlas, 1990.

VANDENBERGHE, Frédéric. Teoria social realista: um diálogo francobritânico. Belo Horizonte: Editora UFMG, 2010. 